\title{
ROLE OF SOCIO-DEMOGRAPHIC AND CULTURAL FACTORS IN KNOWLEDGE, ATTITUDE AND PRACTICE OF USERS ABOUT FAMILY PLANNING METHODS AND SERVICES, RENDERING FROM RURAL PRIMARY HEALTH CARE CENTRE OF BANGLADESH
}

\author{
Mohammad Shamsal Islam', Kourosh Holakouie Naieni ${ }^{2}$, Hassan Eftekhar Ardebili ${ }^{2}$, Abbas Rahimi \\ Foroushani $^{2}$ and Amjad Mirani ${ }^{3}$
}

1'Institute of Community Ophthalmology, University of Chittagong, Bangladesh.
${ }^{2}$ School of Public Health, Tehran University of Medical Sciences, Iran.
${ }^{3}$ Agha Khan University, Karachi Pakistan.
Correspondence: Mohammad Shamsal Islam. Email: msislam009@gmail.com

\begin{abstract}
Background: The socio-demographic and cultural factors closely related with Knowledge, Attitude and Practice (KAP) of users at rural setting. Unfortunately studies on KAP of women about Family planning services from rural setting are almost absent. This study was designed to determine the responsible factors role on KAP of users for receiving family planning services from rural setting of Bangladesh.

Methods: Qualitative descriptive analytical study was employed to follow a structured questionnaire format. A total 420 users were interviewed from two unions. Relevant literatures were reviewed to enhance our understanding of the issue in question. The questionnaires were pretest before finalization and it's has both open and close-ended questions.

Results: The knowledge of users $(87 \%)$ was mostly universal, while community women were more advanced than men. The unmet need for contraception's remains about $16 \%$ and $40 \%$ of mothers to have unintended births. Of all users, Pill was most known methods (68\%), although IUCD (18\%) and condom (14\%) methods were common at community. Side effect (69\%) and husband disapproval (31\%) was barrier of practice of FPMs, although space for child bear (37\%), health problems (30\%), financial problems $(25 \%)$ and education $(8 \%)$ were push factors to users. Approximately $40 \%$ respondents travelled more than 4 kilometer to getting services. Factors were found to be significantly associated with KAP of users were: education $(X 2=29.73 ; p<0.001)$, occupation $(X 2=16.67 ; p<0.001)$ income $(X 2=17.61 ; p<0.011)$ family size $(X 2=25.44 ; p<0.022)$ distance $(X 2=18.75 ; p<0.013)$ cultural beliefs $(X 2=23.84 ; p<0.001$, and accessibility $(X 2=23.67 ; p<0.00)$. Poor practice $(44 \%)$ associated with schooling of users .

Conclusion: Regular yard meeting with users' community and services allied persons may be arranged at community levels for upgrading the existing KAP. Stakeholders' from different ages, genders, and socioeconomic groups have to be engaged to promote evidence-based services. Extensive education and communication programs are needed to address family planning methods and services.

Keywords: Cultural belief, rural setting, affordable, contraceptive, Bangladesh
\end{abstract}

\section{Introduction:}

Bangladesh had started an official Family Planning (FP) programs beginning in 1960s and the programs went through different phases with commendable successes until mid-1990s [1]. Knowledge of FP is almost universal among Bangladeshi married women, although the pace of success has slow down after mid-1990s. The probable reason might be there is a big gap between users Knowledge, Attitude and Practice (KAP) and Family Planning (FP) services providers [2-3]. The gap adversely affected on programs implementation, Contraceptive Rate (CPR), Health of users, and country economy [3]. These gaps are associated with socio-demographic and socio-cultural factors and government programs strategies and policies [4-8]. Major barriers are to adoption of family planning was absent of KAP about contraceptive methods, health side effects and poor effectiveness of the methods. These factors may also argue against increased continuity of contraceptive use. However, culturally appropriate counseling can mobilize the presumably latent demand for contraception by reassuring potential clients of the social acceptability and by allaying their fears about side effects of contraceptive methods [9-11]. The ineffectual programs and socio-cultural related factors affect the KAP of users about FP programs and utilization of RPHC services. The study was designed to determine the importance of KAP of married women about FPMs, services, and suggests guidelines to improve the KAP of users for increase the numbers of CPR. 


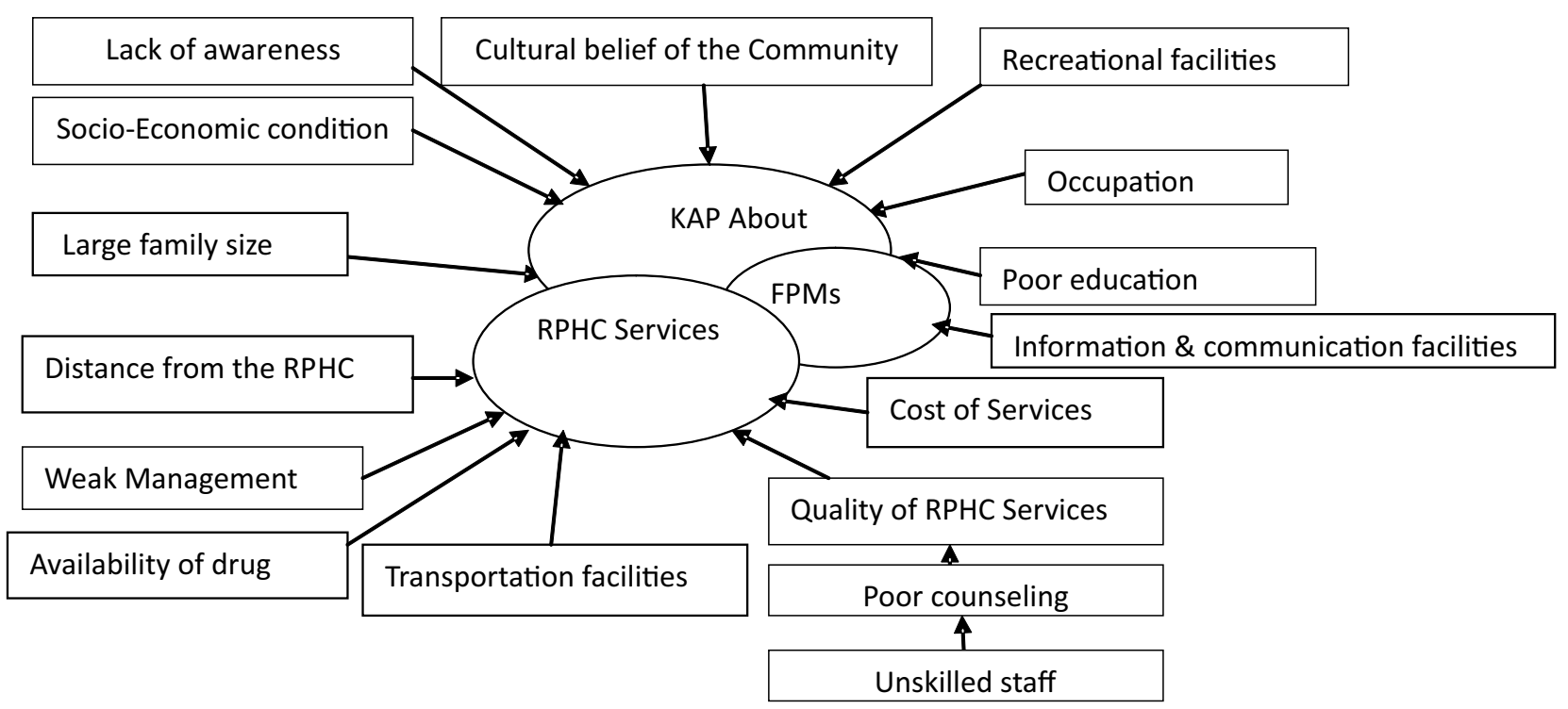

\section{Figure 1. Web of causation of KAP of married women about FPMs and RPHC services}

Knowledge, Attitude and Practice (KAP) towards FP methods and RPHC services are very few and far less on Rural Primary Health Care (RPHC) setting compared to family planning studies in Bangladesh. Relatively KAP of women about FP methods don't lessen its importance as subject of study as it is one of the major causes of poor uptake of family planning methods. We have reviewed limited number of very relevant studies of sub-continent and other selected countries to enhance our understanding of the issue in question. The Socio-demographic factors and socio-cultural factors has strong role on KAP of users regarding FP methods and services of RPHC [3-9]. Formal education and status of occupation has direct influence on KAP of women [10-12] and monthly income and family size encourage users to attend to RPHC services [1, 4, 12]. Misinterpretations of religious and cultural factors are responsible for poor practice of FPMs [12] Husband approval, fears of side effect play vital role in poor uptake of FP methods [9, $11,13]$

\section{Methodology:}

A cross-sectional descriptive analytical study was conducted by face-to-face interviews. A total of 420 married women were drawn as samples from two unions and attendees of those unions RPHC of lakshmipur district using random sampling technique. The questionnaires were pretest before finalization. Data for the study were collected through a simple survey with an interview schedule comprising both open and close-ended questions. Questionnaire on socio-demographic factors (age, sex, education, monthly income, toilet facility, house pattern, distance of RPHC from the users residents, accessibility to RPHC services, family size), cultural factors (religion, false believe etc) and KAP related questions were used to measured the KAP of married women about family planning methods and services of RPHC. This questionnaire contain three domains including knowledge (source of information about FPMs, knowledge about FPMs, knowledge about FP services, and RPHC outdoor environment), attitude (FP staff behavior, mean waiting time, quality of RPHC services and management of RPHC) and practice (problems faced during practice of FPMs, current used FPMs and difficulties of getting services). The data has been analyzed using the Statistical Package for Social Science (SPSS). Descriptive of the results had been carried out using descriptive charts and graphs. Moreover, qualitative statistical tests such as an independent T-Test and Chi-squared had been used for our continuous response (mean score of knowledge, attitude and practice). Multiple regression models have been further used in order to determine different covariates on the outcome variables. For KAP analysis, different segment (Knowledge, attitude and practice) had been also analyzed separately as per required. The project has been approved by the Research Ethics Committee, International campus, Tehran University of Medical Sciences, Iran and District health office, Ministry of Health, Government of Bangladesh.

\section{Results:}

Majority of the respondents (95\%) had schooling and average number of years attending school was 6.32 years. Vast majority respondents (87\%) had good knowledge and attitude about FPMs and services of RPHC but we observed poor practice (44\%) among the users (Table-1).

Pill method (68\%) was most known to users but side effect (69) and husband disapproval (31\%) were barriers to practice of FPMs. We found that adequate 
Table-1: Percentage distribution of Knowledge of users about FPMs and services of RPHC

\begin{tabular}{|l|l|l|l|l|l|l|}
\hline \multirow{2}{*}{ Title of the Question } & \multicolumn{2}{|c|}{ Yes } & \multicolumn{2}{c|}{ I don't Know } & \multicolumn{2}{c|}{ Total } \\
\cline { 2 - 7 } & $\mathrm{N}$ & $\%$ & $\mathrm{~N}$ & $\%$ & $\mathrm{~N}$ & $\%$ \\
\hline $\begin{array}{l}\text { Do you know about family planning } \\
\text { services? }\end{array}$ & 202 & 48.1 & 218 & 51.9 & 420 & 100 \\
\hline $\begin{array}{l}\text { Do you know about family planning } \\
\text { methods? }\end{array}$ & 364 & 86.7 & 56 & 13.3 & 420 & 100 \\
\hline $\begin{array}{l}\text { Do you think that PHC rendered FP } \\
\text { service quality is good? }\end{array}$ & 251 & 59.8 & 169 & 40.2 & 420 & 100 \\
\hline $\begin{array}{l}\text { Do you know, PHC FP services } \\
\text { hours from 9.00 AM to 2.00 PM? }\end{array}$ & 215 & 51.2 & 205 & 49.8 & 420 & 100 \\
\hline $\begin{array}{l}\text { Do you know that PHC outdoor \& } \\
\text { indoor environment is clean and } \\
\text { Healthy? }\end{array}$ & 187 & 44.5 & 233 & 56.5 & 420 & 100 \\
\hline $\begin{array}{l}\text { Do you know that all FP products are } \\
\text { available in the PHC? }\end{array}$ & 19 & 4.5 & 401 & 95.5 & 420 & 100 \\
\hline $\begin{array}{l}\text { Do you know that FP officer must } \\
\text { visit your home weekly? }\end{array}$ & 9 & 2.1 & 411 & 97.9 & 420 & 100 \\
\hline
\end{tabular}

information about family planning methods exits at rural setting of Bangladesh. But they received these information unofficial channels (table-02). Government of Bangladesh routinely disseminated this information through radio, newspapers, magazines, youth groups, community meeting and other public forum. In particular, the information focuses on the role of birth control methods to limit, postpone, and space children, preventing conception, and preventing the acquisition.

Table-2: Percentage distribution of source of information about FPMs and RPHC services

\begin{tabular}{|c|c|c|}
\hline Source of Information & Frequency (F) & Percent (\%) \\
\hline Husband & 141 & 28.3 \\
\hline PHC & 119 & 12.1 \\
\hline Relatives & 51 & 1.9 \\
\hline Media & 08 & 5.0 \\
\hline Neighborhood & 21 & 7.1 \\
\hline Health Workers & 30 & 11.9 \\
\hline Others (social media) & 50 & 100.00 \\
\hline Total & 420 & \\
\hline
\end{tabular}


KAP of respondents has increased with increasing the ages of the respondents. (Knowledge $X 2=6.10, P<.047$; Attitude $\mathrm{X} 2=1.12 \mathrm{P}<0.509$; Practice $\mathrm{X} 2=1.13 \mathrm{P}<0.568$ ). If age of marriage of respondents has increased, the KAP score has uplift.

Table-3: One way ANOVA analysis (Post Hoc Test ) for knowledge, attitude and practice of Respondents opinion facing problem during use of FPMS

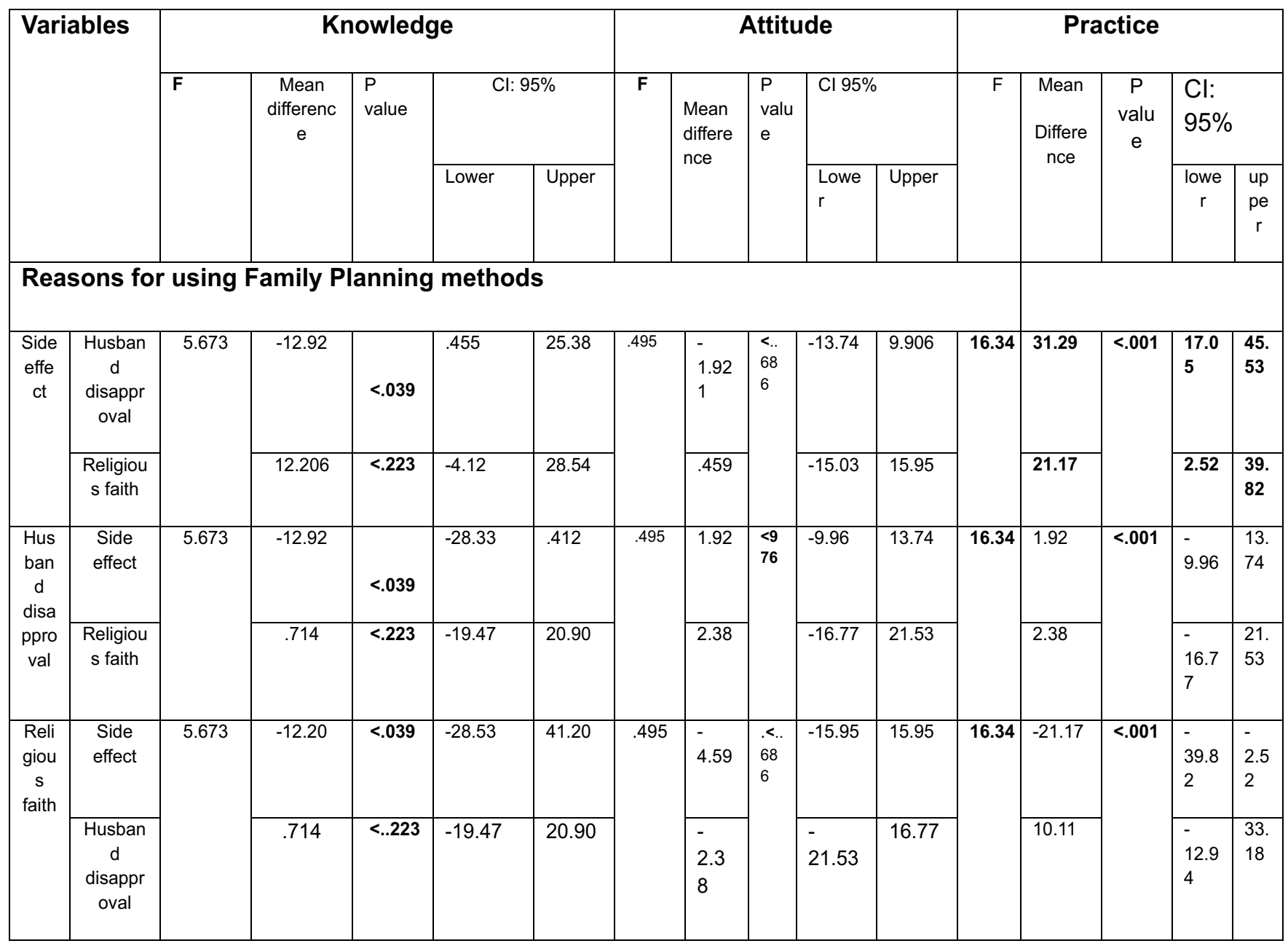

When we compared age of marriage of respondents, we found that $<18$ group KAP score was poor compared to $>18$ years group. Formal education was the most important factor associated with better knowledge about family planning methods (Knowledge X2 = 25.44, $\mathrm{P}<0.001$, Attitude X2 = 11.48, $P<0.022$, Practice $X 2=8.68 P<0.034)$. ). We found that KAP of respondents has increased 2 fold with the increasing of formal education. Occupation strongly associated with knowledge, attitude and practice of married women about family planning methods and services (knowledge $\mathrm{X} 2=16.67 ; \mathrm{P}<0.001$, attitude $\mathrm{X} 2$ $=12.54 ; \mathrm{P}<0.006$, practice $\mathrm{X} 2=.8 .68 ; \mathrm{P}<0.034)$. Above statistical analysis demonstrated that dissemination of information could be effective if family planning counseling program followed by level of education, age and occupation of the users. There is an association between KAP of users and distance of service recipient home ( $($ knowledge $X 2=7.63$; $\mathrm{P}<.05$, attitude $\mathrm{X} 2=12.65 ; \mathrm{P}<0.05$, practice $\mathrm{X} 2=$
5.55; $P<0.136)$. The accessibility of getting services depends on distance between RPHC and users home. Service limitations of RPHC influence the KAP of users. We found that staff good attitude and counseling increase the KAP of users (Knowledge, $\mathrm{f}=$ $7.175 ; P<.001$, attitude $f=11.771 P<.001$, practice $f=$ 12.250; $P<.001)$. Side effect religious faith and husband attitude has significant predicators' role on KAP of users (Table-03).

Discussion: There were two sets of data for the study. One collected from the attendees of the rural primary health care centre and another from the community using In-depth interviews. Although both groups were family planning methods users, they significantly differed in age structure. About $69 \%$ of attendees of RPHC were young aged (21 to 30 years) while community was only $58 \%$ (aged was $30+$ ). This means young age women are more prone to practice family planning methods and attend to centre. From religion context, we found that there is no significance 
difference among Islam and Hindu religion respondents regarding knowledge, attitude and practice of family planning methods and services. This meant that there is no difference among different religions and ethnic groups for getting family planning services from RPHC and they have almost same KAP about family planning methods. Scant of family planning products $(51 \%)$, long waiting time $(42 \%)$, weak management (39\%), lack of female service providers $(48 \%)$, unskilled staff $(44 \%)$, absent of supportive facilities (16\%) appears to be vexing problems for service recipients. Side effect $(69 \%)$ of contraceptive methods and husband disapproval $(31 \%)$ was barriers during practice of family planning methods. The reason could be poor counseling. The contents of the counseling remained to one or two issues, which were definitely inadequate. Of all users, Pill was most known methods $(68 \%)$ to them, although IUCD (18\%) and condom (14\%) methods were common to the users' community. A noticeable respondent has mentioned about side effect $(69 \%)$ and husband disapproval (31\%) as a barrier of practice of family planning methods, although space for child bear (37\%), health problems $(30 \%)$, financial problems $(25 \%)$ and education $(8 \%)$ were push factors to the users regarding use of family planning methods.

Source of information and dissemination of data about new products are important to increase the users' rate at community setting. Findings revealed that source of information were mostly followed by husband $(34 \%)$, RPHC $(28 \%)$, relatives $(12 \%)$, neighborhood $(5 \%)$, health workers $(7 \%)$, social network $(12 \%)$, and media $(1.9 \%)$. The data showed that about $50 \%$ more information was disseminated through unofficial channel. The reason behind might be government poor effort through public channel. For widely dissemination of the information, media, IEC materials, and social network (Face book, Twitter, and Linkedln) could be use. Local religions leader might be vital alternative for effective dissemination of family planning information of Friday prayer time. Some statistically significant differences were found among attendee age, education, income, occupation, family size, accessibility to RPHC services and distance of centre from service recipients. We found that respondents KAP was increased with increasing of ages. Unfortunately about $69 \%$ of girls of Bangladesh got married <18 years [7] and our study findings showed that about $71 \%$ girls went to marry $<18$ years. The possible solution of the problem is that to reform the existing law and extensive education and Behavioral Change and Communication (BCC) programs address to age of marriage. The education also have predictor role on KAP of users. We found that KAP of users has increased two fold, if education level increases from primary level to secondary level. Same findings were conducted at India, Ethiopia,
Nigeria and Cambodia [1, 4, 5, 9]. On an average $40 \%$ respondents were came from 4 Kilometer distance for receiving services from $\mathrm{RPHC}$. We observed that these service recipients were pedestrian. Of our study, we found that about $87 \%$ had good knowledge, $82 \%$ had good attitude and $44 \%$ had good practice. These findings revealed that overall users had good knowledge and attitude but very poor practice level. The possible reasons behind the poor practice are low education, poor awareness program and low coverage of the programs at rural setting.

Conclusion: The nature of KAP findings in the community setting was quite interesting. Among the users about $71 \%$ got married $<18$ years, while national statistics is $69 \%$. Pill was most known methods to them. The most serious concern for users was side effect $(69 \%)$ of the methods. Hence, regular yard meeting with users' community and allied persons involved with RPHC family planning services may be arranged at ward, union and upazila levels for upgrading the existing knowledge, attitudes and practice for selection of appropriate methods. Separate counseling unit about side effect of methods could be effective weapon for increasing the rate of users. All individuals from different ages, genders, and socioeconomic groups have to be engaged to promote evidence-based family planning. These findings suggestive of extensive education and communication programs are need to address misconceptions and myths about family planning methods.

\section{Acknowledgements:}

This work would not have been possible without the commitment of the research team. We also acknowledge the Dean, SPH and Board of ethical research committee TUMS, International campus.

\section{References:}

1. Islam A, Sabu S, Peter W. Men and family planning in Bangladesh: BangladeshDemographic Health Survey 1999-2000; NIPORT and USAID, 2005; BGD 1999 DGS V01M.

2. Parhizkar S, Mahamed F, Shirazi AR. Impact of Family Planning Health Education on the Knowledge and Attitude among Yasoujian Women. Global Journal of Health Science, 2012; Vol. 4, No. 2; doi:10.5539/gjhs.v4n2p110.

3. Khuda B, Chandra NR, Rahman DM. Family Planning and Fertility in Bangladesh, AsiaPacific Population Journal, 2000; 15, no. 1: 41-54

4. Islam S, Hasan M. Women Knowledge, Attitude, Approval of Family Planning and Contraceptive Use in Bangladesh. Asia Pacific Journal of Multidisciplinary Research, 2016; Vol. 4, No. 2.

5. Kamruzzaman M, Hakim A. Family Planning 
Practice Among Married Women Attending Primary Health Care Centers in Bangladesh; International Journal of Bioinformatics and Biomedical Engineering, 2015; Vol. 1, No. 3, 2015, pp. 251-255.

6. Bangladesh Bureau of Statistics (BBS), Government of Bangladesh, Ministry of Planning, Bangladesh, (editorial); 2015, Vol. 01. www.bbs.gov.bd

7. Bangladesh Demographic and Health Survey; Summary report. NIPORT and USAID 2016; $w \mathrm{w} w$. d $\mathrm{g} h \mathrm{~h} \cdot \mathrm{g} O \mathrm{v} \cdot \mathrm{b} d$ : https://dhsprogram.com/pubs/pdf/FR311/FR311 pdf:

8. World Bank Country report. Bangladesh D e velopment U p d a t e , 2015 . www.worldbank.org/en/country/bangladesh

9. Streatfield PK, Kamal N. Population and Family Planning in Bangladesh; Journal of Pakistan Medical Association, 2013; Vol. 63, No. 4

10. Rahman M, Mostafa G, Hoque A. Women's household decision-making autonomy and contraceptive behavior among Bangladeshi women. ELSEVIER, 2014; Volume 5, Issue 1.

11. Gily C, Tizta T, Stanley L, Wonduosen $\mathrm{K}$ et al., Family Planning Knowledge, Attitude and Practice among Married Couples in Jimma Zone, Ethiopia. PLoS One, 2013; 8(4): e61335,

12. Mwaikambo L, Speizer I. Schurmann A, Morgan $G$ and Fikree F., What Works in Family Planning Interventions: A Systematic Review, Studies in Family Planning. NCBI, 2011; Vol.42 No. 2; www.ncbi.nlm.nih.gov/pubmed/21834409

13. Khan T, Khan A., Fertility behavior of women and their house hold characteristics- A case study of Punjab Pakistan. J Hum Ecol, 2010; 30:11-7. 